\title{
Effects of Chronic Lesions in Mesencephalic Raphe Nuclei on Induction of Pseudopregnancy
}

\author{
FUMIHIKO MAEKAWA AND KOREHITO YAMANOUCHI
}

Neuroendocrinology, Department of Basic Human Sciences, School of Human Sciences, Waseda University, Saitama 359, Japan

\begin{abstract}
The role of mesencephalic raphe nuclei in the induction of pseudopregnancy was investigated in female rats. The dorsal or median raphe nucleus lesions (DRL or MRL, respectively) were made by means of a radiofrequency lesion generator. Two or 3 weeks after the operation, in order to induce pseudopregnancy, the vagina was stimulated electrically on the day of proestrus or $1 \mathrm{mg} / \mathrm{kg} \mathrm{b.w}$. reserpine was injected on the day of diestrus I. Traumatization by passing thread to one uterine horn was performed to induce deciduoma 5 days after vaginal stimulation or 3 days after reserpine injection. As the results, decidual response was seen in most control and sham females in both vaginal stimulation and reserpine-treated groups. In contrast, incidences of deciduoma in DRL females with vaginal stimulation or reserpine-injection were significantly lower than those in control and sham groups. In the MRL females with either vaginal stimulation or reserpine-treatment, incidences of deciduoma were comparable to those of the control and sham operated groups. These results suggest that the dorsal raphe nucleus plays an important role in pseudopregnancy-inducing mechanisms in female rats.
\end{abstract}

Key words: Dorsal raphe nucleus, Pseudopregnancy, Deciduoma, Lesion, Vaginal stimulation, Reserpine

(Endocrine Journal 43: 369-374, 1996)

AS IN pregnancy, pseudopregnancy (PSP) is initiated and maintained by diurnal and nocturnal surges of PRL [1-3]. The basic regulatory mechanism for PSP exists in the preoptic area and the medial basal hypothalamus, because destruction of the area [4-5] and interruption of the connecting neural fibers between them [6-9] suppresses the induction and maintenance of PSP.

The onset of pregnancy and PSP requires vaginal stimulation by coitus or by mechanical or electrical stimulation in rats [10]. Instead of vaginal stimulation, depletion of monoamine in the brain by means of a reserpine or chlorpromazine can cause PSP in female rats $[11,12]$. The implan-

Received: December 4, 1995

Accepted: February 26, 1996

Correspondence to: Dr. Korehito YAMANOUCHI, Department of Basic Human Sciences, School of Human Sciences, Waseda University, 2-579-15 Mikajima, Tokorozawa, Saitama 359, Japan tation of reserpine crystals in the median eminence induces PSP [13]. These findings suggest that the depletion of catecholamine, especially dopamine, induces PSP. The noradrenergic system is also involved in the PSP-inducing mechanism, since direct application of catecholaminergic neurotoxin, 6-hydroxydopamine, to the ventral noradrenergic bundle in the pons inhibits the induction of PSP [14].

Moreover, the serotonergic system is concerned with regulation of PSP, based on results showing that treatment with serotonin synthesis inhibitor, p-chlorophenylalanine (PCPA) interrupted PSP [15] and PRL surges during pregnancy [16]. A serotonin receptor antagonist has also been reported to suppress the PRL surges [16]. The mesencephalic raphe nuclei contain a large number of serotonergic neurons [17]. In this experiment, as a first step to elucidate the role of the dorsal and median raphe nuclei in the midbrain on PSP, the chronic lesions were made in these nuclei and decidual responses 
were examined in female rats after electrical stimulation of the vagina or treatment with reserpine.

\section{Materials and Methods}

Female Wistar rats (200-220 g) were housed under controlled temperature $\left(23-25{ }^{\circ} \mathrm{C}\right)$ and illumination (14L:10D, lights on from 0700 to 2100 h). The rats received food and tap water ad libitum. Vaginal smears were taken daily throughout the experiment. Only rats which showed more than two regular 4 day-estrous cycles were used for this experiment.

Fifty-one females were subjected to lesioning of the dorsal raphe nucleus (DRL) or the median raphe nucleus (MRL) under ether anesthesia. The DRL or the MRL was made by means of a radiofrequency lesion generator (RGF-4A, Radionics Inc. Burlington, MA) in 33 and 18 females, respectively. The rats were fixed in a stereotaxic instrument in which the incisor bar was set at $5 \mathrm{~mm}$ below the interaural line. In the DRL group, an electrode $(0.7 \mathrm{~mm}$ in diameter) was lowered $6.8 \mathrm{~mm}$ from the bregma level at a point $7.8 \mathrm{~mm}$ posterior to the bregma on the midline. In the MRL group, the electrode was lowered $8.8 \mathrm{~mm}$ from the bregma level at a point $7.8 \mathrm{~mm}$ posterior to the bregma on the midline. The current was applied and the temperature of the electrode tip was kept at $56^{\circ} \mathrm{C}$ for $1 \mathrm{~min}$ in both groups. In 25 sham-operated control rats, the electrode was lowered to the same point as in the DRL group, but the current was not applied. Twenty-seven females received no brain surgery as the controls.

Two or 3 weeks after the brain surgery, PSP was induced by vaginal stimulation with an electrical stimulator or by injection of reserpine. Vaginal stimulation was performed at $2000 \mathrm{~h}$ on the day of proestrus in 14 control, 13 sham, 15 DRL and 9 MRL females. The rectangular wave currents (167 $\mathrm{Hz}, 10 \mathrm{~V}, 5 \mathrm{msec}$ in duration) were applied for 30 sec by means of a plastic probe $(4.5 \mathrm{~mm}$ in diameter, $280 \mathrm{~mm}$ in length) with 2 current-running regions in the head zone.

A single injection of $1 \mathrm{mg} / \mathrm{kg}$ reserpine (SIG$\mathrm{MA}, \mathrm{R}-0875,1.7 \mathrm{mg} / \mathrm{ml} 1 \%$ acetic acid solvent, $\mathrm{pH}$ 2.4) was given subcutaneously on the morning of diestrus I in 13 control, 12 sham, 18 DRL and 9 MRL rats.

The decidual response was used as a sign of PSP in this experiment. Five days after the vaginal stimulation or 3 days after the reserpine treatment, a silk thread was passed through and placed in the left uterine horn under ether anesthesia to induce deciduoma in all the animals. Four days after the uterine traumatization, the rats were sacrificed with an overdose of diethylether and the decidual response was investigated anatomically and histologically. Weights of the body, left and right uterine horns, ovaries and pituitary were recorded for each rat. The uteri and ovaries were fixed with Bouin's solution, embedded in paraffin, sectioned and stained with hematoxylin-eosin. In order to determine the precise location of the lesions histologically, each brain was removed and fixed in a $10 \%$ formalin solution. Frozen sections were then made and stained with cresyl fast violet. The incidence of deciduoma formation among the groups was analyzed by means of the $\chi^{2}$-test. The weights of organs were compared by analysis of variance followed by Scheffé's post-hoc test with a StatView 4 statistical analysis program (Abacus Concepts Inc., Berkeley, CA).

\section{Results}

After the brain surgery, 15 DRL rats had regular 4 day-estrous cycles but 18 rats with DRL had continuous diestrus for $7.9 \pm 0.8$ (mean \pm SEM) days. After this period, regular estrous cycles reappeared in these DRL animals. In the MRL group, 6 of 18 rats also had continuous diestrus for $6.7 \pm 1.1$ days. In all sham rats, the regular 4 day-estrous cycles continued after the brain surgery.

\section{PSP by vaginal stimulation}

All females showed signs of vaginal estrus on the day after vaginal stimulation. In the control group, 12 of 14 rats had constant vaginal diestrus from 2 days after vaginal stimulation until autopsy and had massive deciduoma in the traumatized uterine horn (Table 1). Two other control females had regular 4 day-estrous cycles after vaginal stimulation, and no decidual cells were observed in the uterine horn. As well as the control, all of the sham females had continuous vaginal diestrus and the incidence of positive decidual reaction was high. In contrast, the incidence of decidual formation was lower in DRL rats than in the control and 
Table 1. Effects of mesencephalic raphe nucleus lesions on induction of pseudopregnancy by vaginal stimulation

\begin{tabular}{|c|c|c|c|c|c|c|}
\hline \multirow[b]{2}{*}{ Groups } & \multirow[b]{2}{*}{$\begin{array}{l}\text { No. } \\
\text { of rats }\end{array}$} & \multicolumn{2}{|c|}{ Deciduoma response } & \multicolumn{3}{|c|}{ Weight of uterine horn $(\mathrm{mg} / 100 \mathrm{~g}$ b.w. } \\
\hline & & Incidence & $(\%)$ & & $\begin{array}{c}\text { Control } \\
(\text { Mean } \pm \text { SEM })\end{array}$ & $\begin{array}{c}\text { Traumatized } \\
\text { (Mean } \pm \text { SEM) }\end{array}$ \\
\hline Control & 14 & $12 / 14$ & 85.7 & $\begin{array}{l}(+)^{* *} \\
(-)\end{array}$ & $\begin{array}{c}54.0 \pm 2.7 \\
102.6\end{array}$ & $\begin{array}{c}160.7 \pm 20.1 \\
113.6\end{array}$ \\
\hline Sham & 13 & $11 / 13$ & 84.6 & $\begin{array}{l}(+) \\
(-)\end{array}$ & $\begin{array}{c}58.5 \pm 4.8 \\
114.1\end{array}$ & $\begin{array}{c}152.6 \pm 20.8 \\
121.1\end{array}$ \\
\hline DRL & 15 & $7 / 15^{*}$ & 46.7 & $\begin{array}{l}(+) \\
(-)\end{array}$ & $\begin{array}{l}43.2 \pm 2.8 \\
97.3 \pm 5.0\end{array}$ & $\begin{array}{l}191.5 \pm 26.4 \\
118.4 \pm 11.0\end{array}$ \\
\hline MRL & 9 & $9 / 9$ & 100 & $\begin{array}{l}(+) \\
(-)\end{array}$ & $\begin{array}{c}56.1 \pm 4.0 \\
-\end{array}$ & $\begin{array}{c}167.8 \pm 23.6 \\
-\end{array}$ \\
\hline
\end{tabular}

${ }^{*} P<0.05$ vs. Control and Sham, $P<0.01$ vs. MRL $\left(\chi^{2}\right.$-test $) .{ }^{*}(+)$ : rats with deciduoma, $(-)$ : rats without deciduoma.

Table 2. Effects of mesencephalic raphe nucleus lesions on induction of pseudopregnancy by reserpine

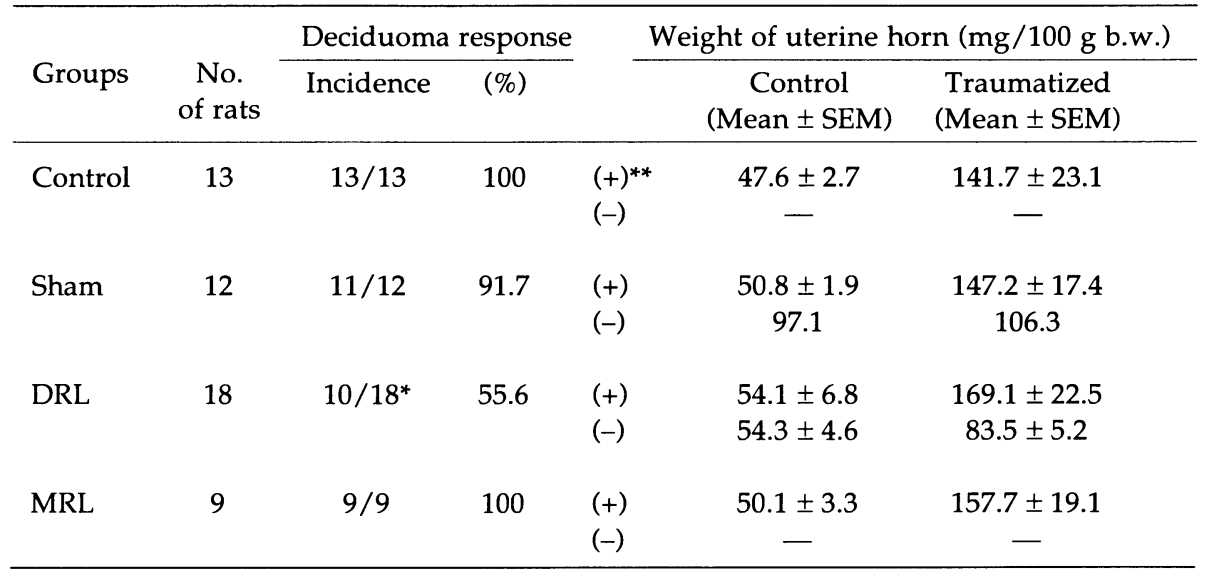

${ }^{*} P<0.01$ vs. Control, $P<0.05$ vs. Sham and MRL $\left(\chi^{2}\right.$-test). ${ }^{* *}(+)$ : rats with deciduoma, $(-)$ : rats without deciduoma.

sham groups $(P<0.05)$. The decidual cells are observed in only 7 out of 15 DRL females. Eight DRL rats without deciduoma had regular 4 dayestrous cycles. In all the MRL rats, deciduoma and constant vaginal diestrus were observed.

\section{PSP by reserpine}

As in the vaginal stimulation groups, the incidence of deciduoma in the DRL group was lower than in the other groups (Table 2). All or most of the reserpine-treated control or sham females had massive deciduoma and had continuous vaginal diestrus. On the other hand, decidual formation did not occur in 8 of 18 DRL females, the incidence being lower than in the control and sham groups $(P<0.01, P<0.05$, respectively), but all DRL females had vaginal diestrus until autopsy. In the MRL group, deciduoma was observed in all females with constant vaginal diestrus after reserpine treatment.

There were no significant differences in the weights of ovaries and pituitaries among the groups in the rats with vaginal stimulation $(\mathrm{F}(3$, $48)=1.6,1.2$, respectively) and with reserpine $(F(3$, $47)=0.8,0.9)$. The body weights were also found 

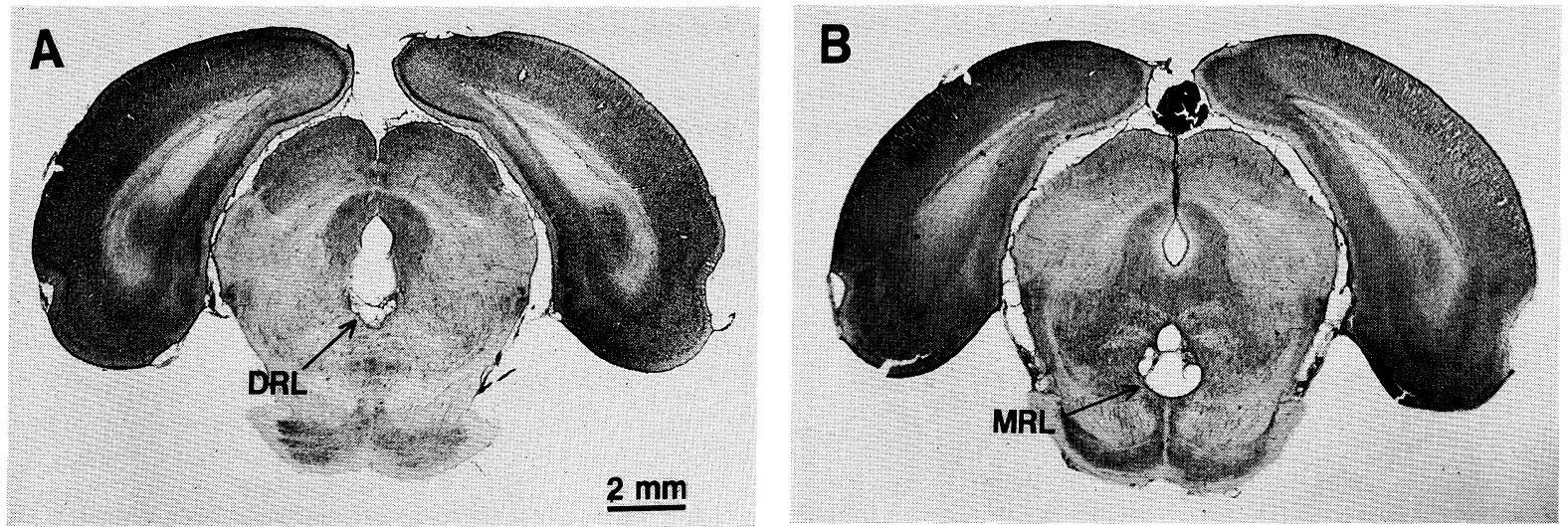

Fig. 1. Photomicrographs of representative frontal sections of the midbrain in rats with DRL (A) and MRL (B) (No. 17, No. 38, cresyl fast violet stain). Arrows indicate the DRL and the MRL.

to show no difference among groups in rats with vaginal stimulation and with reserpine $(\mathrm{F}(3$, $48)=1.4, F(3,47)=2.3$, respectively).

\section{Histological examination of the brain}

The location of the brain lesion was determined histologically following the brain atlas of Paxinos and Watson [18]. In the DRL group, the lesions were seen at the level from the oculomotor nucleus to the locus coeruleus on the midline of the midbrain (Fig. 1A). Most of the dorsal raphe nucleus and the adjacent areas were damaged. In a few DRL females, lesions penetrated to the decussation of the superior cerebellar peduncle or the ventral central gray. The median raphe nucleus was intact in all DRL rats. The location of the lesions in DRL rats with deciduoma does not seem to differ from those in DRL rats without deciduoma. In the MRL group, the lesions were located from the level of the caudal tip of the interpeduncular nucleus to the raphe pontis nucleus on the midline of the midbrain (Fig. 1B). Most of the median raphe nucleus and a part of the adjacent pontine reticular nucleus were damaged. In a few animals, the medial lemniscus and pontine nucleus were partially lesioned. The dorsal raphe nucleus was intact in the MRL group.

\section{Discussion}

In this experiment, the incidence of decidual for- mation after electrical stimulation of the vagina in the DRL group was lower than in the control and MRL groups. Similar results were obtained in the groups in which PSP was induced by reserpine. These results suggest that the dorsal raphe nucleus plays an imporiant role in the onset of PSP in rats.

The dorsal raphe nucleus contains a large number of serotonin neurons which send their axons to the forebrain. Depletion of brain serotonin by treatments with PCPA before an injection of reserpine resulted in a decrease in the incidence of decidual formation [15]. As in PSP, the suppressive effect of PCPA on pregnancy has been reported [16]. The diurnal and nocturnal surges of PRL which are induced by vaginal stimulation or a treatment with reserpine are most important in maintaining rat PSP $[2,10]$. The nocturnal surge is blocked by PCPA or the serotonin receptor blocker, ketanserin [16]. The serotonergic system is therefore thought to play a facilitatory role in the maintenance of PRL surges. The dorsal raphe nucleus lesions have been reported to suppress the suckling-induced PRL increase and estrogen-induced afternoon PRL surge in female rats $[19,20]$. In addition, lesions of the dorsal raphe nucleus inhibit the PRL-releasing effect of serotonin in male rats [21, 22]. These studies support the speculation that serotonin neurons in the dorsal raphe nucleus are responsible for the activation of PRL secretion in the PSP.

Reserpine is thought to act on the hypothalamus and to stimulate PRL secretion, because direct im- 
plantation of reserpine into the medial basal hypothalamus causes PSP [13]. The PRL secretion from the pituitary is regulated by medial basal hypothalamic dopaminergic neurons which send their axons to the median eminence [23]. Since dopamine plays an inhibitory role in regulating PRL secretion [23], one of explanations for the induction of PSP by reserpine is the decrease in dopamine activity in the median eminence. The function of the serotonergic system in facilitating PRL secretion is thought to be mediated primarily by hypothalamic dopamine neurons, because the application of serotonin to the ventricle decreased expression of the dopamine synthesis enzyme messenger RNA in the medial basal hypothalamus [24]. The hypothalamus contains many nerve terminals of the serotonin neurons in the dorsal raphe nucleus [25]. From these reports, it can be thought that the decrease of serotonin by the dorsal raphe nucleus lesions in the hypothalamus prevents the PSP-inducing function of reserpine.

Nocturnal and diurnal surges in PRL require the signals from the preoptic area to the hypothalamus, because destruction of the preoptic area [4-5] or interruption of the connecting fibers between the preoptic area and the hypothalamus suppressed the PRL surges during pregnancy and interrupted PSP [6-9]. The existence of nerve terminals of the fibers from the dorsal raphe nucleus had also been verified in the preoptic area $[17,26,27]$. The vaginal stimulation is reported to facilitate metabolic activity in the dorsal raphe nucleus [28] and FOS protein expression in the preoptic area $[29,30]$. These findings suggest the possibility that the se- rotonergic neurons in the dorsal raphe nucleus play an important role as the relay station in sending signals for the induction of PSP from the vagina to the preoptic area. On the other hand, the noradrenergic neurons also have been reported to play a facilitatory role in regulating PRL secretion, since PSP cannot be induced in female rats with the ventral noradrenergic bundle lesions by 6-hydroxydopamine [14] or by cutting in the ventral tegmentum of the midbrain [31], even when vagina is stimulated. In addition, treatment with acetylcholine receptor agonist before mechanical stimulation of the vagina on the day of estrus results in the failure to induce PSP [10]. The dorsal raphe nucleus contains a small number of noradrenergic neurons [17]. Cholinergic neurons also exist in the ventral central gray of the midbrain [17]. The possibility that the suppressive effect of the dorsal raphe nucleus lesions is due not only to the destruction of the serotonergic function but also to interruption of the function of noradrenergic and cholinergic neurons cannot be excluded. Further experiments on quantifying the PRL and neurotransmitters are need to clarify these points.

\section{Acknowledgments}

This study was supported by a Grant-in-Aid No. 056407456 to K. Y. from the Ministry of Education, Science and Culture of Japan and Waseda University Grant No. 96A-300 for Special Research Projects.

\section{References}

1. Freeman ME, Neill JD (1972) The pattern of prolactin secretion during pseudopregnancy in the rat: A daily nocturnal surge. Endocrinology 90: 1292-1294.

2. Freeman ME, Smith MS, Nazian SJ, Neill JD (1974) Ovarian and hypothalamic control of the daily surges of prolactin secretion during pseudopregnancy in the rat. Endocrinology 94: 875-882.

3. MacLeod RM (1976) Regulation of prolactin secretion. In: Martini L, Ganong WF (eds) Frontiers in Neuroendocrinology. Raven Press, New York, 4: 169-194.

4. Watanabe H, Furuya $H$, Okada R, Yamanouchi K, Arai $Y$ (1980) Interruption of pseudopregnancy by rostral periventricular preoptic lesions in the fe- male rat. Endokrinologie 76: 181-184.

5. Kawakami M, Arita J (1981) Circadian rhythm of prolactin surges induced by stimulation of the uterine cervix in the ovariectomized rat: Its sexual differentiation and preoptic regulation. J Endocr 91: 325-334.

6. Jakubowski M, Dow RC, Fink G (1988) Preoptichypothalamic pathways controlling nocturnal prolactin surges, pseudopregnancy, and estrous cyclicity in the rat. Neuroendocrionlogy 47: 13-19.

7. Arai Y (1969) Effect of hypothalamic deafferentiation on induction of pseudopregnancy by vaginal-cervical stimulation in the rat. J Reprod Fert 19: 573-575. 
8. Arai Y, Yamanouchi K (1975) Possible role of anterior inputs to the medial basal hypothalamus $(\mathrm{MBH})$ in regulating prolactin release during pseudopregnancy in the rat. Brain Res 83: 51-58.

9. Carrer HF, Taleisnik S (1970) Induction and maintenance of pseudopregnancy after interruption of preoptic hypothalamic connections. Endocrinology 86: 231-236.

10. Terkel J (1986) Neuroendocrinology of coitally and noncoitally induced pseudopregnancy. In: Komisaruk BR, Siegel HI, Cheng M-F, Feder $\mathrm{HH}$ (eds) Reproduction: A Behavioral and Neuroendocrine Perspective. The New York Academy of Sciences, New York, 76-94.

11. Barraclough CA, Sawyer CH (1959) Induction of pseudopregnancy in the rat by reserpine and chloropromazine. Endocrinology 65: 563-571.

12. Coppola JA, Leonardi RG, Lippmann W, Perrine JW, Ringler I (1965) Induction of pseudopregnancy in rats by depletors of endogenous catecholamines. Endocrinology 77: 485-490.

13. van Maanen JH, Smelik PG (1968) Induction of psuedopregnancy in rats following local depletion of monoamines in the median eminence of the hypothalamus. Neuroendocrinology 3: 177-186.

14. Hansen S, Stanfield EJ, Everitt BJ (1981) The effects of lesions of lateral tegmental noradrenergic neurons on components of sexual behavior and pseudopregnancy in female rats. Neuroscience 6: 1105-1117.

15. Maekawa F, Yamanouchi K (1996) Effects of deprivation of serotonin by $p$-chlorophenylalanine on induction and maintenance of pseudopregnancy in female rats. Brain Res Bull 39: 317-321.

16. Mistry AM, Voogt JL (1990) Serotonin synthesis inhibition or receptor antagonism reduces pregnancy-induced nocturnal prolactin secretion. Life Sci 47: 693-701.

17. Törk I (1985) Raphe nuclei and serotonin containing systems. In: Paxinos G (ed) The Rat Nervous System. Academic Press, New York, 2: 43-78.

18. Paxinos G, Watson C (1986) The Rat Brain in Stereotaxic Coordinates. 2nd ed, Academic press, San Diego.

19. Barofsky AL, Taylor J, Massari VJ (1983) Dorsal raphe-hypothalamic projections provide the stimulatory serotonergic input to suckling-induced prolactin release. Endocrinology 113: 1894-1903.
20. Pan JT, Gala RR (1987) The influence of raphe lesions, $p$-chlorophenylalanine, and ketanserin on the estrogen-induced afternoon prolactin surge. Endocrinology 120: 2070-2077.

21. Fessler RG, Deyo SN, Meltzer HY, Miller RJ (1984) Evidence that the medial and dorsal raphe nuclei mediate serotonergically-induced increases in prolactin release from the pituitary. Brain Res 299: 231-237.

22. Avis JP, Simpkins JW, Bennett J, Meites J (1978) Serotonergic control of prolactin release in male rats. Life Sci 24: 359-366.

23. Freeman ME (1994) The neuroendocrine control of the ovarian cycle of the rat. In: Knobil E, Neill JD (eds) The Physiology of Reproduction. 2nd ed, Raven Press, New York, 613-657.

24. Mathiasen JR, Arbogast LA, Voogt JL (1992) Central administration of serotonin decreases tyrosine hydroxylase catalytic activity and messenger ribonucleic acid signal levels in the hypothalamus of female rats. J Neuroendocrinol 4: 631-639.

25. Azmitia EC, Segal M (1978) An autoradiographic analysis of the differential ascending projections of the dorsal and medial raphe nuclei in the rat. $J$ Comp Neur 178: 641-668.

26. Ajika K, Ochi J (1978) Serotonergic projections to the suprachiasmatic nucleus and the median eminence of the rat: Identification by fluorescence and electron microscope. J Anat 127: 563-576.

27. Vertes R (1991) A PHA-L analysis of ascending projection of the dorsal raphe nucleus in the rat. J Comp Neur 313: 643-668.

28. Allen TO, Adler NT, Greenberg JH, Reivich M (1981) Vaginocervical stimulation selectively increases metabolic activity in the rat brain. Science 211: 1068-1072.

29. Tetel MJ, Getzinger MJ, Blaustein JD (1993) Fos expression in the rat brain following vaginal-cervical stimulation by mating and manual probing. $J$ Neuroendocrinol 5: 397-404.

30. Erskine MS (1993) Mating-induced increases in FOS protein in preoptic area and medial amygdala of cycling female rats. Brain Res Bull 32: 447-451.

31. Kawakami M, Arita J (1982) Midbrain pathways for the initiation and maintenance of the nocturnal prolactin surge in the pseudopregnant rats. Endocrinology 110: 1977-1982. 